Will man dieser Anschauung folgen, so könnte man die Geschwulst als ein Fibroma papillare diffusum bezeichnen. Will man diese kleinzellige Wucherung dagegen auf eine Entzündung der Schleimbaut zurüekführen und die zottenförmige Oberfächenwucherung als den Ausdruck einer solchen erachten, so wäre mit Rücksicht auf das Primäre der Ausdruck Pyelitis villosa vorzuziehen.

Weiter möchte ich noch die Blutextravasate im Gewebe einer Besprechung würdigen. Da sich in der Nachbarschaft derselben die Bindegewebszüge in keiner Weise verändert zeigen und gerade da keinerlei Pigmentirungen und Zellenproliferationen vorhanden sind, da ferner die rothen Blutkörperchen noch sehr deutlich erkennbare Formen haben, möchte ich annehmen, dass die Extravasate vielleicht durch Läsionen bei der Operation hervorgerufen wurden.

Nach diesen Ausführungen glaube ich mich berechtigt, die Prognose des Falles als eine günstige zu bezeichnen.

\title{
B erichtigung.
}

Zu Bd. 147 S. 535 ist folgende Berichtigung zu geben:

Durch ein Versehen des Lithographen ist die Numerirung der Figuren auf den Tafeln eine unrichtige geworden. Als Fig. 1 ist die Figur auf Taf. XIII zn bezeichnen. Die Numerirung der Figuren auf Taf. XIV und XV sollte mit der Nummer 2 beginnen, so dass also statt der beigedruckten Zahlen jedes Mal die năchstfolgende Ziffer zu setzen ist. Nur so stimmt der Text der "Erklărung der Abbildungen" mit der Bezeichnung der Figuren überein. Auf Taf. XIII Fig. 1 ist statt $\mathrm{H}, \mathrm{O}^{\prime \prime} \mathrm{zu}$ setzen. 